\title{
CLINICAL PATTERN OF INTRA-CRANIAL SPACE OCCUPYING LESION IN TERTIARY LEVEL HOSPITAL
}

\author{
DATTA PK ${ }^{1}$, SUTRADHAR SR ${ }^{2}$, KHAN NA ${ }^{3}$, HOSSAIN MZ ${ }^{4}$, SUMON SM ${ }^{5}$, HASAN I ${ }^{6}$, DATTA \\ $\mathrm{R}^{7}$,ANWAR AT ${ }^{8}$, ISLAM $\mathrm{R}^{9}$, ELAHI ME ${ }^{10}$
}

\begin{abstract}
Background : The term "Intra-cranial space occupying lesion" (ICSOL) is defined as any neoplasm, benign or malignant, primary or secondary, as well as any inflammatory or parasitic mass lying within the cranial cavity. Advances in intracranial imaging have made the detection of intracranial lesions relatively accurate and enabling us to focus on the etiology of these space-occupying lesions. Many reports suggested that both incidence and pattern of intracranial space occupying lesions are subject to considerable geographic and racial variations. Knowledge of the regional peculiarities of these lesions will help in identifications of possible risk factors.
\end{abstract}

Materials and Methods: This observational study was done in the department of medicine of Mymensingh medical college hospital, Bangladesh from November, 2011 to April, 2012 to evaluate the clinical pattern of ICSOL among the 75 adult admitted patients. Patient aged more than 15 years of either sex with symptoms and signs of ICSOL and at least one CT or MRI evidence in favour of diagnosis were included.

Results: The highest participation (22.7\%) was observed from 55-64 years age group. Mean age of the participants was $54.35 \pm 18.68$ years. Neoplastic tumor was (25.8\%) in 15-24 years age group and non neoplastic lesion was (31.8\%) in 55-64 years age group, among participants (76.0\%) came from rural areas and 24\% from urban. Population regarding the occupation $30.7 \%$ were housewives, $21.3 \%$ were service holders and $20.0 \%$ are farmers. Headache was the most common symptom noted in $93.33 \%$ of patients. Nausea/ vomiting, difficulty in limb movement and imbalance were the other most common three symptoms. In this series intracerebral hemorrhage was found in 53.3\% of patients, Astrocytoma was the second most common (20.0\%). Meningioma was found in $8 \%$ of the participants and another $8 \%$ had metastatic lesions in their brain. There were two cases of schwanoma while tuberculoma was diagnosed in another two participants (2.7\%).

Conclusion: Patients with symptoms and signs of ICSOL should be dealt with great care and CT or MRI helps to evaluate them for early diagnosis and proper management.

J Dhaka Med Coll. 2019; 28(1) : 17-22

1. Dr. Ponkaj Kanti Datta, Clinical pathologist, Department of Laboratory Medicine, Dhaka Medical College Hospital, Dhaka

2. Dr. Satya Ranjan Sutradhar, Professor, Department Of Medicine, Mymensingh Medical College, Mymensingh

3. Dr. Md. Nur-a-alam khan, Associate Professor, Department Of Medicine, Mymensingh Medical College, Mymensingh

4. Dr. Mohammad Zaid Hossain, Associate professor, Dhaka Medical College, Dhaka

5. Dr. Sultan Mahamud Sumon, Medical officer, Transfusion Medicine Department ,Dhaka Medical College Hospital, Dhaka

6. Dr. Imrul Hasan, FCPS (Medicine), Assistant Professor, Department Of Medicine, Mymensingh Medical College, Mymensingh

7. Dr. Raj Datta, Consultant, Dhaka medical college Hospital, Dhaka

8. DR. A S M Tanim Anwar, Registrar, department of Nephrology, Dhaka medical college, Dhaka

9. Dr. Rezaul Islam, Emergency Medical Officer, Dhaka medical college Hospital, Dhaka

10. Dr. Md. Monjur-e-Elahi, FCPS(Medicine),Junior consultant, Department of Medicine, Dinajpur Medical College \& Hospital, Dinajpur

Correspondence: Dr. Ponkaj Kanti Datta, Clinical pathologist, Department Of Laboratory Medicine, Dhaka Medical College Hospital, Dhaka, Bangladesh.Email: ponkajdatta@yahoo.com.

Received: 10 February $2019 \quad$ Revision: 02 March 2019

Accepted: 30 Mach 2019

DOI: https://doi.org/10.3329/jdmc.v28i1.45751 


\section{Introduction}

The term "Intra-cranial space occupying lesion" is defined as any neoplasm, benign or malignant, primary or secondary, as well as any inflammatory or parasitic mass lying within the cranial cavity ${ }^{1}$. The list also includes haematomas ${ }^{2}$ different types of cysts, ${ }^{3,4}$ and vascular malformations $5,1,6$. Intra-cranial space occupying lesion (ICSOL) is also known as intra-cranial mass lesions. ICSOL can be broadly classified into neoplastic lesions and non-neoplastic lesions ${ }^{7}$. Common nonneoplastic causes of ICSOL are InfectiveCerebral abscess (pyogenic, toxoplasma etc.), tuberculoma, cysticercosis, echinococosis (as hydatid cyst), schistosomiasis; traumatic subdural haematoma, extdural haematoma; vascular- intracerebral haematoma; Inflammatory - sarcoid mass; and others arachnoid cyst, colloid cyst, embryonic dysplastic lesions (craniopharyngioma, hamartoma) ${ }^{8}$. Common primary neoplastic lesions are astrocytoma, meningioma, schwanoma, pituitary adenoma although brain and vertebral metastases from systemic cancer are far more prevalent than primary tumors. About $15 \%$ of patients who die of cancer have symptomatic brain metastases; an additional $5 \%$ suffer spinal cord involvement ${ }^{10}$.

Among the ICSOL, tuberculoma is very much common in the developing countries but in developed world cerebral neoplasms are more frequent. ${ }^{8}$ A study carried out by Neuropathology department, institute of neurological science, Glasgow, among 2.7 milion populations over 5 years shows the incidence of anaplastic astrocytoma $40 \%$, meningioma $15 \%$, metastasis $12 \%$, astrocytoma $8 \%$ and Pituitary adenoma $4 \%$ in adults. Among the infratentorial tumors schwanoma is the most common (6\%). Metastasis is $4 \%$ - being the second most common. ${ }^{9}$

A patient with intracranial space occupying lesion may present with local effects of the mass on adjacent brain tissue (e.g. seizures, focal signs) - the symptoms depend on the site of the lesion.Features of raised intracranial pressure: headache, impairment of conscious level ,papilloedema, vomiting, bradycardia, arterial hypertension, and false localising signs: pupillary dilatation (ipsilateral to lesion), 6th cranial nerve lesion (unilateral or bilateral), hemiparesis (ipsilateral to lesion), bilateral extensor plantar responses ${ }^{8}$ may be presenting feature.

Diagnosis of intra-cranial space occupying lesion is done by compatible history, relevant examination findings and appropriate investigations. Advances in cranial imaging have made the detection of intracranial lesions relatively accurate and enabling us to focus on the etiology of these space-occupying lesions. Over the past three decades, many reports suggested that both incidence and pattern of intracranial space occupying lesions are subject to considerable geographic and racial variations. Knowledge of the regional peculiarities of these lesions will help in identifications of possible risk factors; demographic characteristics will also help in establishing measures for the correct diagnosis of ICSOL in this region. Very few accurate statistics reporting the clinical pattern of intracranial space occupying lesions are available in Bangladesh. Therefore, this study is designed to find out the clinical pattern of intra-cranial space occupying lesions.

\section{Materials and methods:}

This observational study was done in the department of Medicine of Mymensingh medical college hospital over the period of 6 months, from 1st November, 2011 to $30^{\text {th }}$ April, 2012 to evaluate the clinical pattern of ICSOL among the adult admitted patient. A total number of 75 cases were included in this study. Patient aged more than 15 years of either sex with symptoms and signs of ICSOL and at least one $\mathrm{CT}$ or MRI evidence in favour of diagnosis were included. The term "Intra-cranial space occupying lesion" is defined as any neoplasm, benign or malignant, primary or secondary, as well as any inflammatory or parasitic mass lying within the cranial cavity. Patient aged less than 15 years or refused to do the investigation needed for diagnosis were excluded. Samples were taken by purposive way. Consent was taken from the patient or from their legal attendants and ethical consideration was approved by authorized ethical committee. A structured data collection form was developed 
containing all the variables of interest which was finalized following pre testing. Data were collected by interview, observation, clinical examination and investigations. Data were processed and analyzed by using SPSS (Statistical Package for Social Science) 15.0. The test statistics were measured by Chi-square (c2) Test. The level of Significance was set at 0.05.

\section{Result}

Age distribution:

The highest participation (22.7\%) was observed from 55-64 years age group. Mean age of the participants was $54.35 \pm 18.68$ years. Neoplastic tumor was most common (25.8\%) in 15-24 years age group and non neoplastic lesion was most common $(31.8 \%)$ in $55-64$ years age group (Table-I).

Table-I

Age distribution of the participants

\begin{tabular}{lcc}
\hline $\begin{array}{l}\text { Age of the } \\
\text { patients } \\
\text { (years) }\end{array}$ & $\begin{array}{c}\text { Type of ICSOL } \\
\mathrm{n}=31\end{array}$ & $\begin{array}{c}\text { Non neoplastic } \\
\mathrm{n}=44\end{array}$ \\
\hline $15-24$ & $8(25.8 \%)$ & $2(4.5 \%)$ \\
$25-34$ & $3(9.7 \%)$ & $2(4.5 \%)$ \\
$35-44$ & $2(6.5 \%)$ & $2(4.5 \%)$ \\
$45-54$ & $5(16.1 \%)$ & $6(13.6 \%)$ \\
$55-64$ & $3(9.7 \%)$ & $14(31.8 \%)$ \\
$65-74$ & $6(19.4 \%)$ & $9(20.5 \%)$ \\
75 and above & $4(12.9 \%)$ & $9(20.5 \%)$ \\
\hline
\end{tabular}

Sex distribution:

$54.8 \%$ of all males and $63.6 \%$ of all females have non neoplastic lesions.

\section{Distribution of residence:}

Among the participants most (76.0\%) came from rural areas and $24 \%$ from urban areas.

\section{Distribution of occupation:}

Among the participants irrespective of sex, $30.7 \%$ are housewives constituting the largest group, $21.3 \%$ are service holders and $20.0 \%$ are farmers. But sex wise distribution showed that farmers $(36.7 \%)$ constituted the largest group among male and housewives (69.7\%) constituted the largest group among female participants.

\section{Distribution of the symptoms:}

Headache was the most common symptom noted in $93.33 \%$ of patients. Nausea/ vomiting, difficulty in limb movement and imbalance were the other most common three symptoms. More than one symptom was noted in all most all patients. (Table-II)

Table-II

Distribution of patient according to presenting Symptoms

\begin{tabular}{lcc}
\hline Symptoms & No. of cases & Percentage \\
\hline Headache & 70 & 93.3 \\
Nausea/ Vomiting & 66 & 88.0 \\
Difficulty in limb & 51 & 68.0 \\
movement & & \\
Imbalance & 44 & 58.7 \\
Aphasia & 36 & 48.0 \\
Convulsion & 25 & 33.3 \\
Mental change & 21 & 28.0 \\
Disturbance of & 18 & 24.0 \\
consciousness & & \\
Fever & 8 & 10.7 \\
Visual disturbance & 6 & 8.0 \\
Vertigo & 4 & 5.3 \\
Cough & 4 & 5.3 \\
Ear discharge & 1 & 1.3 \\
Weight gain & 1 & 1.3 \\
\hline
\end{tabular}

\section{Distribution of ICSOL by morphological diagnosis based on CT/ MRI:}

Among the ICSOL, intracerebral haemorrage was most commonly (53.3\%) diagnosed depending on the morphological features observed on CT scan/ MRI. .Astrocytoma was the second most common (20.0\%) ICSOl. Meningioma was found in $8 \%$ of the participants and another $8 \%$ had metastatic lesions in their brain. There were two cases of schwanoma $(2.7 \%)$ while tuberculoma was diagnosed in another two participants based on CTscan/ MRI findings. (Table-III). While considering the neoplastic tumors alone, Astrocytoma was the most common (48.4\%). Meningioma was $19.40 \%$, metastatic tumors $19.40 \%$, schwanoma $6.5 \%$, arterio-venous malformation 
$3.2 \%$, pituitary adenoma $3.2 \%$ among all neoplastic tumors. Infective causes of ICSOL were observed less commonly. Tuberculoma was most common of them. It was only $2.7 \%$ of all ICSOL. Brain abscess and hydatid cyst was far less common (1.3\%). (Table-IV and V)

\section{Table- III}

Distribution of tumors by CI/ MRI diagnosis

\begin{tabular}{lcc}
\hline Type of ICSOL & Frequency & Percent \\
\hline Astrocytoma & 15 & 20.0 \\
Meningioma & 6 & 8.0 \\
Schwanoma & 2 & 2.7 \\
A-V malformation & 1 & 1.3 \\
Pituitary adenoma & 1 & 1.3 \\
Metastatic tumors & 6 & 8.0 \\
Intracerebral haemorrage & 40 & 53.3 \\
Tuberculoma & 2 & 2.7 \\
Brain abscess & 1 & 1.3 \\
Hydatid cyst & 1 & 1.3 \\
\hline Total & 75 & 100.0 \\
\hline
\end{tabular}

Table-IV

Frequency of neoplastic tumors

\begin{tabular}{lcc}
\hline Type of neoplastic tumors & Frequency & Percent \\
\hline Astrocytoma & 15 & 48.4 \\
Meningioma & 6 & 19.4 \\
Schwanoma & 2 & 6.5 \\
Arterio-venous malformation & 1 & 3.2 \\
Pituitary adenoma & 1 & 3.2 \\
Metastatic tumors & 6 & 19.4 \\
\hline Total & 31 & 100.0 \\
\hline
\end{tabular}

Table-V

Frequency of non neoplastic lesions

\begin{tabular}{lcc}
\hline $\begin{array}{l}\text { Types of non } \\
\text { neoplastic lesions }\end{array}$ & Frequency & Percent \\
\hline Intracerebral haemorrage & 40 & 90.9 \\
Infective causes & 4 & 9.1 \\
\hline Total & 44 & 100.0 \\
\hline
\end{tabular}

\section{Discussion}

This study was done to evaluate the clinical pattern of ICSOL in tertiary level hospital of Bangladesh. In this study, Mean age of the participants was $54.35 \pm 18.64$ years. Highest participation was observed from 55-64 years age group (neoplastic $9.7 \%$ and non-neoplastic $31.8 \%$ ). Highest number of the neoplastic lesions was found in 15-24 years age group. Non neoplastic lesions were found in 55-64 years age group in highest number. Male female ratio was 1.27:1. This result was consistent with a study conducted in Pakistan in 1999 where $54 \%$ participants were male. Although, highest participation was noted from third decade, a steep rise of number of cases in the sixth decade was also observed. ${ }^{7}$ This study is also consistent with other studies in home and also in abroad, like in Nairobi, Kenya ${ }^{11}$.

The present study is not consistent with another study done in Karachi, Pakistan. They analyzed 386 cases and found ICSOL more commonly in 11-20 years age group. This discrepancy might be due to inclusion of participants from all age group ${ }^{19}$. Another study at Riyadh, Saudi Arabia showed maximum occurrence of ICSOL in fourth decade and male female ratio was 1.45:1. Although sex distribution was consistent with present study, the age distribution was not consistent. It might be due to the inclusion of $12 \%$ participants from age group less than 15 years ${ }^{1}$.

Regarding the residence of the participants, the present study showed that most of the participants came from rural areas $(76 \%)$ is consistent with the study done at BSMMU, Dhaka (2006-2007) by Mollah N et al. They found that $70 \%$ of the participants came from the rural areas $^{10}$.

In this study, headache was found to be the most common (93.33\%) symptoms. Nausea/ vomiting, difficulty in limb movement, imbalance, aphasia, convulsion, mental change and disturbance of consciousness was also noted. Fever was found in only $10.67 \%$ of participants. Visual disturbances, vertigo, cough, ear ache and weight gain were also noted in minority of the participants. Headache and vomiting were noted as the two most common 
symptoms in many studies. Other symptoms noted here were also more or less similar to other studies ${ }^{10,11,12,15}$. But in a Polish study, the most frequent manifestation were psychic changes and neurological deficit signs (hemiperesis). The study showed that intracranial raised pressure syndrome was rather infrequent, with the exception of headache. This finding is not consistent with present study. It might be due to the fact that polish study only analyzed the clinical course of malignant brain tumor in patients aged over 50 years $^{16}$.

In the present study, intracerebral haematoma was the most common ICSOL. It was found in $53.3 \%$ of the participants. It was also the most common (90.9\%) non neoplastic lesion. Astrocytoma was the second most common $(20.0 \%)$ ICSOl. Meningioma was found in $8 \%$ of the participants and another $8 \%$ had metastatic lesions in their brain. There were two cases of schwannoma while tuberculoma was diagnosed in another two participants based on CTscan/ MRI findings. But among the neoplastic tumors, Astrocytoma was the most common (48.40\%). Meningioma was $19.40 \%$, metastatic tumors $19.40 \%$, schwannoma $6.50 \%$, arterio-venous malformation $3.20 \%$, pituitary adenoma $3.20 \%$ among all neoplastic tumors. Infective causes of ICSOL were observed less commonly. Tuberculoma was most common of them. It was only $2.7 \%$ of all ICSOL. Brain abscess and hydatid cyst was even less common (1.3\%). A morphological analysis of 100 cases of intra-cranial space occupying lesion was conducted in Pakistan; $89 \%$ patient had neoplastic lesion and $11 \%$ had non neoplastic lesion. Among the neoplastic lesions neuroepitelial tumor (41\%) was most frequent of which more than $80 \%$ was astrocytomas. Other neoplastic tumors were meningiomas (23\%), nerve sheet tumours (Schwannomas) $(11 \%$,$) primary adenomas (2 \%)$, vascular tumours $(1 \%)$, arterio-venous malformation (1\%), extension from regional tumours $(2 \%)$, metastatic Tumours $(6 \%)$, germ cell tumours (1\%), lymphomas( $1 \%)$. Tuberculoma was the most frequent in non neoplastic group. Other non neoplastic tumors are fungal infection $(2 \%)$, cysts $(2 \%)$, haemorrhages $(2 \%)$, cholesteatoma
(1\%), and chronic infection (1\%). On the basis of the total number of ICSOL, the percentage for most of the brain tumor was much lower in the present study than the study in Pakistan. ${ }^{7}$ This is also true for most other studies $1,10,11,14,17,18,19,20$. Most of those studies were done in neurology or neurosurgery wards and they excluded intracerebral hemorrhage as a cause of ICSOL from their study. But the present study was conducted in medicine ward of a tertiary level hospital where emergency admission in neurology and neurosurgery ward was not available. So, most cases of intracerebral hemorrhage were admitted in medicine as acute stroke cases and subsequently diagnosed as space occupying lesion due to intracerebral haematoma on CT scan of brain or MRI of brain. As a result, the total number of nonneoplastic lesion became higher and neoplastic tumors became lower as compared to other studies. But when the neoplastic lesion alone was considered, the percentages of all tumor entities reached a level comparable to that reported by others ${ }^{1,10}, 11$, $14,17,18,20$.

Two large Indian study showed that tuberculoma was the most common infective cause of ICSOL which is consistent with the present study. ${ }^{13,15}$ In one study, it was mentioned that among all ICSOL the percentage for most brain tumours found in their study was much lower than the figures given in other series from countries where the incidence of tuberculoma is very low. ${ }^{13}$ This might not be true for the present study as the number of tuberculoma cases were not very high in this series. This result was consistent with the result of a study in Kuwait. Their study showed intracranial tuberculoma was present in 1.4\% of all ICSOL. ${ }^{21}$ Another Indian study showed the maximum number of patients of ICSOL belonged to malignant etiology of $19(37 \%)$ while 14 patients $(27 \%)$ belongs to benign nature, 11 patients $(21 \%)$ were belonged to infective etiology and 8 patients were of traumatic etiology (15\%). Among the all benign tumors the distribution was 9\% tuberculoma, $1 \%$ hydatid cyst, $1 \%$ abscess and $11 \%$ infective etiologies. ${ }^{15}$ Though the number of total malignant tumor could not be shown due to 
lack of histopathology, the distribution of other neoplastic and infective ICSOL is more or less similar to the present study. The number of intracerebral hemorrhage cases could not be compared as they did not include them in their study.

\section{Conclusion}

In this study it is found that non neoplastic lesion more than neoplastic lesion. Rural peoples, housewife and age above 50 years are mostly affected. A very non specific neurological symptom like headache was observed in most of the participants. So, careful history taking, meticulous clinical examination and imaging (CT/MRI) will be helpful in the evaluation of the patient of ICSOL. Further large scale study will be required to draw a conclusion about the actual clinical pattern of ICSOL in Bangladesh.

\section{References}

1. Jamjoom ZAB. Pattern of intra-cranial space occupying lesions: experience at King Khalid University Hospital. Ann Saudi Med 1989; 9: 3-10

2. Duncan G, Caird F. Review of 18 years experience of a diagnostic geriatricneurology referral service. ScotMed-J 1991; 36: 139-42

3. Darrel F, Weinman. Incidence and Behaviour Pattern of intra-cranial Tumours in Ceylon. International Surgery J 1973; 58: 548-54

4. Conley FK. Epidermiod and dermiod tumours: Clinical features and surgical management. In: Wilkins R.H. and Rengachary S.S, editors. Neurosurgery Vol. No. 1. 2nd Ed. New York: McGrawHill; 1996. 971-76

5. Wen-Qing QQ, Shi-Jow, Qing-sheng T, et al. Statistical analysis of central nervous system tumours in China. J Neurosurg 1982; 56 (4): 555-64

6. Lombardi D, Scheithauer BW, Piepgras D, et al. Angioglioma and the arteriovenous malformationglioma association. Journal of Neurosurgery 1991; 75: 589-96

7. Butt ME, Khan SA., Chaudrhy NA, et al. Intra-cranial space occupying lesions a morphological analysis. Biomedica 2005 ; 21:31-6

8. Allen CMC, Lueck CJ, Dennis M. Neurological disease. In: Colledge NR, Walker BR, Ralston SH, editors. Davidson's Principles and Practice of Medicine. $21^{\text {st }}$ edition. China: Elsevier Limited; 2010. 1215
9. Lindsay KW, Bone I. Neurology and Neurosurgery illustrated. $4^{\text {th }}$ edition. China: Elsevier Limited; 2004. 299-318

10. Mollah N, Baki A, Afzal N, Hossen A. Clinical and Pathological Characteristics of Brain Tumor. BSMMU J 2010; 3(2): 68-71

11. Mwang'ombe NJ, Ombachi RB. Brain tumours at the Kenyatta National Hospital, Nairobi. East Afr Med J 2000; 77(8): 444-7

12. Debnath H, Barua KK, Hossain MA, Khair MA, Islam MA. Outcome and Prognosis of Metastatic Brain Tumour: A Study of 35 Cases. Bangladesh Journal of Neuroscience 2008; 24 (1): 17-23

13. Darab KD, Lalitha V S, Prabhakar V. Pathological analysis of intracranial space-occupying lesions in 1000 cases including children. Journal of the Neurological Sciences 1968; 6(3): 575-92

14. Irfan A, Qureshi A. Intracranial space occupying lesions-review of 386 cases. J Pak Med Assoc 1995; 45(12): 319-20

15. Rathod V, Bhole A, Chauhan B, Ramteke H, Wani B. Study of clinico-radiological and clinico-pathological correlation of intracranial space occupying lesion at rural center. The Internet Journal of Neurosurgery 2010; $7(1): 23-7$

16. Mierzejewska E. Clinical pattern of malignant brain tumors in patients over 50 years of age. Neurol Neurochir Pol 1976; 10(6): 738-42

17. Khan MA, Panju SA, Enam SA. Spectrum of intracrnial pathology: tumors versus infections at a tertiary care hospital. Pak J Neurol Sci 2007; 2(1):610

18. Ahmed Z, Muzaffar S, Kayani N, Pervez S, Husainy AS, Hasan SH. Histological pattern of central nervous system neoplasms. J Pak Med Assoc 2001 Apr; 51(4):154-7

19. Watson CW, Hajdu SI. Cytology of primary neoplasms of the central nervous system. Acta Cytol 1977 Jan; 21(1): 40-7

20. Shah SH, Soomro IN, Hussainy AS, Hassan SH. Clinico-morphological pattern of intracranial tumors in children. J Pak Med Assoc 1999 Mar; 49(3): 63-5.

21. Abdul-Ghaffar NU, E1-Sonbaty MR, Rahman NA.Intracranial tuberculoma in Kuwait. Int J Tuberc Lung Dis 1998 May; 2(5): 413-8

22. Eyenga VC, Ngah JE, Atangana R, Etom E, Ngowe MN, Bassong Y, Oyono JL, Sosso M. Central nervous system tumours in Cameroon: histopathology and demography. Sante 2008 Jan; 18(1): 39-42

23. Surawicz TS, McCarthy BJ, Kupelian V, Jukich PJ, Bruner JM, Davis FG. Descriptive epidemiology of primary brain and CNS tumors: results from the Central Brain Tumor Registry of the United States, 1990-1994. Neuro Oncol 1999 Jan;1(1):14-25 